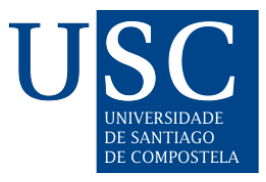

Dereito: revista xurídica da Universidade de Santiago de Compostela, 30(2), 2021. ISSN-e: 2174-0690

https://doi.org/10.15304/dereito.30.2.7576

Estudios

\title{
INCONSTITUCIONALIDADE DA TARIFAÇÃO DO VALOR DOS DANOS EXTRAPATRIMONIAIS INTRODUZIDA PELA REFORMA TRABALHISTA NO BRASIL
}

\section{UNCONSTITUTIONALITY OF THE TARIFF SYSTEM TO CALCULATE THE VALUE OF THE EXTRAPATRIMONIAL DAMAGES INTRODUCED BY THE LABOR REFORM IN BRAZIL INCONSTITUCIONALIDAD DEL TARIFACIÓN DEL VALOR DE LOS DAÑOS MORALES INTRODUCIDOS POR LA REFORMA LABORAL EN BRASIL}

\author{
VINÍCIUS NACIF BARBOSA ${ }^{1, \mathrm{a}}$ (D), BRUNO GOMES BORGES DA FONSECA ${ }^{2, \mathrm{~b}}$ (i) \\ ${ }^{1}$ Graduado em Direito pela Faculdade de Direito de Vitória, Brasil \\ ${ }^{2}$ Professor da graduação e da pós-graduação da Faculdade de Direito de Vitória (Brasil), Procurador do Trabalho na 17a Região, \\ Brasil \\ a viniciusnacif.097@gmail.com ${ }^{\mathrm{b}}$ bgbfonseca@yahoo.com.br
}

\section{Resumo}

Esta pesquisa analisou a constitucionalidade da tarifação dos danos extrapatrimoniais decorrentes das relações de trabalho. Essa previsão foi introduzida pela Reforma Trabalhista ocorrida no Brasil em 2017. 0 estudo definiu os danos extrapatrimoniais na perspectiva do ordenamento jurídico brasileiro, apresentou a alteração promovida pela Reforma Trabalhista relativa à introdução da tarifação do valor do dano moral a partir do salário do respectivo trabalhador lesado e examinou decisões dos tribunais superiores sobre o tema, inclusive os argumentos constantes da ação direta de inconstitucionalidade 6050 cujo pedido foi o de declarar a inconstitucionalidade dessa nova previsão normativa. Ademais, a partir da dialética, foram expostos fundamentos defensores da constitucionalidade e da inconstitucionalidade do novo preceito. 0 estudo concluiu, com base no princípios da reparação integral dos danos, da proporcionalidade e da dignidade da pessoa humana, que é inconstitucional a previsão normativa de tarifação do valor do dano moral no direito do trabalho.

Palavras-chave: dano moral; quantificação; reparação integral.

\begin{abstract}
This research analyzed the constitutionality of the tariff system to calculate extrapatrimonial damages resulting from labor relations. This law was introduced by the Labor Reform that occurred in Brazil in 2017. The study defined the extrapatrimonial damages from the perspective of the Brazilian legal system, presented the change promoted by the Labor Reform on the introduction of tariff rates to calculate the value of moral damage based on the salary of the respective injured worker and examined decisions of the higher courts on the subject, including the arguments presented in the direct action of unconstitutionality
\end{abstract}


6050, whose claim was to declare the unconstitutionality of this new normative forecast. Moreover, based on dialectics, the arguments defending both the constitutionality and the unconstitutionality of the new precept were exposed. The study concluded, based on the principles of full reparation of damages, of proportionality and of dignity of the human person, that the normative provision of a tariff for moral damages in labor law is unconstitutional.

Keywords: moral damage; quantification; full repair.

\section{Resumen}

Esta investigación analizó la constitucionalidad de la tarifación del valor de los daños morales resultante de las relaciones laborales. Esta previsión fue introducida por la Reforma Laboral hecha en Brasil en 2017. El estudio definió los daños morales desde la perspectiva del sistema jurídico brasileño, presentó el cambio promovido por la Reforma Laboral cerca la introducción de la tarifación del valor del daño moral desde el salario del trabajador lesionado, y examinó las decisiones de los tribunales superiores sobre el tema, incluyendo los argumentos contenidos en la acción directa de inconstitucionalidad 6050 cuya demanda ha sido declarar la inconstitucionalidad de esta nueva previsión normativa. Además, desde la dialéctica, los fundamentos fueran expuestos a la constitucionalidad e inconstitucionalidad del nuevo precepto. El estudio concluyó, sobre la base de los principios de reparación plena de los daños, proporcionalidad y dignidad de la persona humana, que es inconstitucional predecir la disposición normativa de tarifación del valor del daño moral en el derecho laboral.

Palabras clave: daño moral; cuantificación; reparación completa.

\section{INTRODUÇÃO}

A Lei $13.467 / 2017,{ }^{1}$ mais conhecida como Lei da Reforma Trabalhista, trouxe importantes alterações no ordenamento jurídico trabalhista brasileiro. A ideia inicialmente veiculada é a de que tais alterações seriam benéficas para os trabalhadores, contudo a lei é polêmica em diversos pontos. Em muitos dispositivos, há nítida precarização das condições de trabalho e restrição ao acesso do trabalhador à jurisdição.

Este estudo, a título de recorte, analisa um dos pontos mais questionados da Reforma Trabalhista ocorrida no Brasil em 2017: a taxatividade do valor fixado a título de dano extrapatrimonial, cuja abrangência consiste em estabelecer parâmetros objetivos para a fixação judicial do quantum indenizatório.

Essa taxatividade é uma das inovações trazida pela Reforma Trabalhista. Depois da Constituição Federal de 1988 (CF/1988), ${ }^{2}$ inexistiam dispositivos legais que tratassem a respeito da tarifação do dano extrapatrimonial. A Consolidação das Leis do Trabalho (CLT), com a alteração legislativa, passa a dispor a respeito de um limite para a fixação, pelo juiz do trabalho, do quantum indenizatório, no que se refere ao dano extrapatrimonial, conforme se extrai do artigo 223-G da CLT. ${ }^{3}$

A pesquisa se justifica pela necessidade de analisar se a tarifação do dano extrapatrimonial, como estatuída na CLT, é um preceito compatível com a Constituição brasileira de 1988.

Esta pesquisa adota o método dialético. A abordagem dialética deve ser compreendida como uma maneira de reconhecer contradições e antagonismos ínsitos à vida material, que acabam por se reproduzir na ordem jurídica. 
Relativavemente à técnica de pesquisa, adota-se a documental indireta nas modalidades pesquisas documental e bibliográfica, ou seja, para a confecção deste estudo analisa documentos públicos, estatísticas, fontes normativas e bibliografia tornada pública.

Este texto é dividido em três seções. A primeira analisa, na perspectiva do ordenamento jurídico brasileiro, os danos extrapatrimoniais. A segunda analisa a taxatividade desses danos, imposta pela Reforma Trabalhista, além de expor os argumentos da ação direta de inconstitucionalidade (ADI) $6050^{4}$ em trâmite perante o Supremo Tribunal Federal (STF) cuja pretensão é declarar como inconstitucional a previsão de tarifação do dano extrapatrimonial. A última seção, por fim, responde ao problema gerador desta pesquisa.

\section{ASPECTOS GERAIS DO DANO EXTRAPATRIMONIAL}

Esta seção abordará os aspectos gerais do dano extrapatrimonial com o objetivo de trazer elementos teóricos capazes de contribuir para resposta do problema desta pesquisa.

\subsection{A reparabilidade integral dos danos morais}

É possível diferenciar a categoria dos danos patrimoniais (ou materiais), de um lado, dos chamados danos extrapatrimoniais (ou morais), de outro. Conforme entendimento de Carlos Roberto Gonçalves: < [...] material é o dano que afeta somente o patrimônio do ofendido. Moral é o que só ofende o devedor como ser humano, não lhe atingindo o patrimônio $>.^{5}$

Nesse passo, a definição de dano extrapatrimonial sob a perspectiva de Correia e Miessa: $<$ Conforme exposto no art. 223-A, o dano extrapatrimonial é gênero, dos quais são espécies o dano moral, o estético e o existencial. Enquanto o dano estético é uma alteração corporal interna ou externa que causa desagrado ou repulsa à vítima, como também à pessoa que a observa, o dano moral é de ordem psíquica, pertencente ao foro íntimo da pessoa. Por sua vez, o dano existencial é o prejuízo causado a uma atividade não remunerada da pessoa com a violação de um direito inviolável tutelado constitucionalmente>. ${ }^{6}$

0 dano extrapatrimonial decorre da tutela da dignidade da pessoa humana que é um valor protegido constitucionalmente: $<$ A dignidade é um valor espiritual e moral inerente à pessoa, que se manifesta singularmente na autodeterminação consciente e responsável da própria vida e que traz consigo a pretensão ao respeito por parte das demais pessoas, constituindo-se em um mínimo invulnerável que todo estatuto jurídico deve assegurar, de modo que, somente excepcionalmente, possam ser feitas limitações ao exercício dos direitos fundamentais, mas sempre sem menosprezar a necessária estima que merecem todas as pessoas enquanto seres humanos $>{ }^{7}$

Assim, o dano moral não se restringe somente a dor, o vexame e a tristeza. Pode se caracterizar pela violação de bens imateriais, como a imagem, o nome, entre outros direitos da personalidade. Para caracterização do dano moral, faz-se necessário que um ato ilícito acarrete danos à esfera da personalidade da vítima, havendo, assim, um nexo de causalidade entre a conduta e a lesão.

Os danos morais são configurados a partir de condutas ilícitas que resultam em danos à esfera psíquica do ofendido, na medida em que afetam o patrimônio imaterial dos indivíduos, sendo este, portanto, um direito personalíssimo, previsto no artigo 186 do Código Civil Brasileiro. ${ }^{8}$ 
Nesse sentido, Carlos Roberto Gonçalves aduz: <Dano moral é o que atinge o ofendido como pessoa, não lesando seu patrimônio. É lesão de bem que integra os direitos da personalidade, como a honra, a dignidade, intimidade, a imagem, o bom nome, etc., como se infere dos art. 1ํㅡ, III, e 5ํㅡ, V e X, da Constituição Federal, e que acarreta ao lesado dor, sofrimento, tristeza, vexame e humilhação $>{ }^{9}$

Evidencia-se que atos ofensivos aos direitos inerentes à personalidade dos indivíduos, ensejam indenizações por danos morais, pois o patrimônio imaterial das vítimas, bem como o material, são bens jurídicos tutelados pelo ordenamento jurídico pátrio.

Nas palavras de Nader, foi com a CF/1988 que se passou a reconhecer os danos morais no ordenamento jurídico brasileiro: <Em termos legislativos, foi com a Constituição Federal de 1988 que o dano moral logrou expresso reconhecimento em nosso país. Ao apontar 'a dignidade da pessoa humana' como um dos fundamentos da República Federativa (art. 1ํㅡ, inc. III), optou por uma filosofia humanista e, ao assegurar o direito à reparação pelo dano moral, tornou prática e eficaz a proteção à pessoa humana . $^{10}$

A tese pela reparabilidade dos danos imateriais tornou-se pacífica com a CF/1988. Antes disso, existia um cenário teórico e pragmático de impossibilidade de reparação dos danos morais, em detrimento das dificuldades de enxergar suas determinações e quantificações.

Com a CF/1988, houve grande evolução quanto ao tema, ao consagrar os danos extrapatrimoniais, conforme disposto no artigo 5ํㅡ, V e X: <Art. 5ํ․ Todos são iguais perante a lei, sem distinção de qualquer natureza, garantindo-se aos brasileiros e aos estrangeiros residentes no País a inviolabilidade do direito à vida, à liberdade, à igualdade, à segurança e à propriedade, nos termos seguintes: [...] V - é assegurado o direito de resposta, proporcional ao agravo, além da indenização por dano material, moral ou à imagem; [...] X - são invioláveis a intimidade, a vida privada, a honra e a imagem das pessoas, assegurado o direito a indenização pelo dano material ou moral decorrente de sua violação>.

Patenteia-se, com isso, a tutela constitucional dada aos danos morais no ordenamento jurídico brasileiro. Além disso, os incisos $\mathrm{V}$ e X do artigo 5으 da CF/1988 asseguram o direito a uma indenização ampla e proporcional dos danos extrapatrimoniais, em conformidade com o princípio constitucional da reparação integral.

Acerca da reparação integral, Sanseverino registra: < [...] o princípio da reparação integral ou plena constitui a principal diretriz do operador do direito para orientar a quantificação da indenização pecuniária>. ${ }^{11}$

No que tange às indenizações por danos morais, o princípio supracitado possui a finalidade de reparar integralmente os danos sofridos pelas vítimas, a partir da compensação pecuniária dos prejuízos decorrentes dos atos ilícitos.

A reparação integral dos danos deve se atentar aos princípios da proporcionalidade e da razoabilidade, isto é, o quantum indenizatório deve ser proporcional ao agravo, além de ser mensurado conforme a dimensão dos danos, nos termos do Código Civil brasileiro: <Art. 944. A indenização mede-se pela extensão do dano>.

\subsection{Diferentes formas de tarifação dos danos extrapatrimoniais}

No ordenamento jurídico brasileiro, o Código Brasileiro de Telecomunicações ${ }^{12}$ e a Lei de Imprensa ${ }^{13}$ previam um valor tarifado a título de danos morais, mas com a promulgação da 
CF/1988, aparentemente, o novo ordenamento jurídico rejeitou a tarifação do dano moral. A rigor, passou-se a entender que a indenização decorrente do dano moral deveria ser ampla e exata na proporção da ofensa.

De acordo com o entendimento do STF, na arguição de descumprimento de preceito fundamental (ADPF) 130, ${ }^{14}$ e do Superior Tribunal de Justiça (STJ), na Súmula 281: <A indenização por dano moral não está sujeita à tarifação prevista na Lei de Imprensa $>,{ }^{15}$ a indenização por dano moral não está sujeita a tarifação, porquanto a CF/1988 assegura a reparação integral do dano.

O Ministro Ricardo Lewandowski, no julgamento da citada ADPF 130, registrou: <Esta Suprema Corte, no tocante à indenização por dano moral, de longa data, cristalizou jurisprudência no sentido de que o art. 52 e 56 da Lei de Imprensa não foram recepcionados pela Constituição, com o que afastou a possibilidade do estabelecimento de qualquer tarifação, confirmando, nesse aspecto, a Súmula 281 do Superior Tribunal de Justiça>.

O STF possuía, antes de julgar a ADPF 130, decisões com sinais de que seu entendimento era pela inconstitucionalidade da tarifação dos danos morais, conforme extraído da decisão proferida no recurso extraordinário (RE) 396386: $<$ [...] o que deve ser tomado em linha de conta é que a Constituição de 1988 emprestou ao dano moral tratamento especial - C.F., art. 5o , V e X - desejando que a indenização decorrente desse dano fosse a mais ampla. Posta a questão nesses termos, considerado o tratamento especial que a Constituição emprestou à reparação decorrente do dano moral, não seria possível sujeitá-las aos limites estreitos da lei de imprensa>. ${ }^{16}$

O STJ, além da sobredita súmula, decidiu pela inaplicabilidade da tarifação da indenização por danos morais, decorrentes do transporte aéreo, entendimento exposto no recurso especial (REsp) 347449: <É que prevalece o entendimento de ser a indenização por danos morais, decorrente de simples atraso de voo ou situações equivalentes, como temporário extravio de bagagem, ao fim recuperada, moldada pelas regras dispostas na legislação nacional, afastada a tarifação prevista na Convenção de Varsóvia>. ${ }^{17}$

Parece possível, portanto, concluir que, no Brasil, a Suprema Corte e o STJ possuem entendimento consolidado no sentido de que o valor decorrente de danos morais não pode ser tarifado. Consequentemente, os valores indenizatórios devem ser concedidos de forma ampla e proporcional, com inadmissão de qualquer forma de tarifação desses danos.

\section{DANOS EXTRAPATRIMONIAIS NA PERSPECTIVA DO ORDENAMENTO JURÍDICO TRABALHISTA}

O objetivo desta seção é tratar dos danos extrapatrimoniais de uma maneira mais específica embasado no ordenamento jurídico trabalhista. 0 direito do trabalho, na condição de um ramo especial, parte da CF/1988, dialoga com o Código Civil, possui como pontos chaves a dignidade da pessoa humana e o direito ao trabalho ${ }^{18}$ e traz muitas particularidades que o distigue dos demais ramos jurídicos. A abordagem se apropriará das lições expostas anteriormente e carreará outras mais aproximadas do direito do trabalho. 


\subsection{Taxatividade dos danos extrapatrimoniais sobre o prisma da reforma trabalhista}

O instituto dos danos morais se encontra previsto na legislação trabalhista. Inclusive, o legislador constitucional reconheceu a competência da Justiça do Trabalho para julgar demandas relativas às indenizações por danos extrapatrimoniais, frutos das relações de trabalho, conforme estabelece o art. 114, VI, da CF/1988: < [...] Compete à Justiça do Trabalho processar e julgar: [...] VI as ações de indenização por dano moral ou patrimonial, decorrentes da relação de trabalho.>

Além da competência para apreciar e julgar pleitos indenizatórios por danos morais, a Reforma Trabalhista inseriu um novo título à CLT: o Título II-A. Nesse passo, o artigo 223-A da CLT restringe a aplicação do instituto dos danos extrapatrimoniais, provenientes da relação de trabalho, apenas às hipóteses de incidências contidas no Título supracitado, conforme redação do dispositivo em questão: "Aplicam-se à reparação de danos de natureza extrapatrimonial decorrentes da relação de trabalho apenas os dispositivos deste Título".

O legislador, ao redigir os dispositivos do novo Título II-A da CLT, os isolou das demais normas do direito comum, colidindo com os preceitos fundamentais da CF/1988 e do próprio ordenamento jurídico trabalhista, cujo $§ 1^{\circ}$ do artigo 8ํㅜㄹ da CLT admite a aplicação subsidiária do Código Civil. A ressalva de Bezerra Leite é relevante: <Por essa razão, pensamos que os arts. 223-A a 223-G devem ser interpretados conforme os valores, princípios e regras da Constituição Federal e do Código Civil, sempre que implicarem melhoria da condição social, econômica e ambiental dos trabalhadores (CF, arts. $1^{\circ}$, $5^{\circ}$, $7^{\circ}$, caput, 200, VIII, e 225)>. ${ }^{19}$

Os bens juridicamente tutelados são elencados de forma exemplificativa nos artigos 223-C e 223D da CLT: <Art. 223-C da CLT. A honra, a imagem, a intimidade, a liberdade de ação, a autoestima, a sexualidade, a saúde, o lazer e a integridade física são os bens juridicamente tutelados inerentes à pessoa física. Art. 223-D da CLT. A imagem, a marca, o nome, o segredo empresarial e o sigilo da correspondência são bens juridicamente tutelados inerentes à pessoa jurídica>.

A dinamicidade dos fatos presentes na sociedade moderna, na qual as relações inter-humanas sofrem mudanças ao longo do tempo, resultando em situações nas quais o Direito não consegue abarcar, não sendo possível, portanto, prever todos os casos de incidência do instituto dos danos extrapatrimoniais na sociedade contemporânea. Portanto, os dispositivos contidos no Título II-A da CLT são conflitantes com a dinamicidade do Direito, na medida em que o legislador é incapaz de delimitar todos os cenários ensejadores de indenização por danos extrapatrimoniais, diante das particularidades que permeiam as relações de trabalho.

Evidenciam-se inúmeros problemas das previsões introduzidas pela Reforma Trabalhista ao regulamentar a aplicação do instituto dos danos extrapatrimoniais, bem como no que tange à proteção da pessoa humana.

O cerne da análise, contudo, diz respeito à tarifação do valor do dano extrapatrimonial imposta pela Reforma Trabalhista: <Art. 223-G [...] §1ํ. Se julgar procedente o pedido, o juízo fixará a indenização a ser paga, a cada um dos ofendidos, em um dos seguintes parâmetros, vedada a acumulação: I - ofensa de natureza leve, até três vezes o último salário contratual do ofendido; II - ofensa de natureza média, até cinco vezes o último salário contratual do ofendido; III - ofensa de natureza grave, até vinte vezes o último salário contratual do ofendido; IV - ofensa de natureza gravíssima, até cinquenta vezes o último salário contratual do ofendido. §2‥ Se o ofendido for pessoa jurídica, a indenização será fixada com observância dos mesmos parâmetros estabelecidos 
no $§ 10$ deste artigo, mas em relação ao salário contratual do ofensor. §3ํ․ Na reincidência entre partes idênticas, o juízo poderá elevar ao dobro o valor da indenização>.

No entendimento de Tartuce, os danos morais ou extrapatrimoniais não devem conter limitação de valor, ou seja, não é coerente a determinação de um preço para o sofrimento: <Constituindo o dano moral uma lesão aos direitos da personalidade (arts. 11 a 21 do CC), para a sua reparação não se requer a determinação de um preço para a dor ou o sofrimento, mas sim um meio para atenuar, em parte, as consequências do prejuízo imaterial, o que traz o conceito de lenitivo, derivativo ou sucedâneo. Por isso é que se utiliza a expressão reparação e não ressarcimento para os danos morais, conforme outrora foi comentado. Desse modo, esclareça-se que não há no dano moral uma finalidade de acréscimo patrimonial para a vítima, mas sim de compensação pelos males suportados>. ${ }^{20}$

A indenização por dano moral não objetiva ressarcir os danos causados, mas sim compensar os efeitos decorrentes das lesões à esfera psíquica das vítimas.

0 caput do art. 223-G da CLT estabelece um rol que deverá ser levado em conta pelo juiz do trabalho para o arbitramento do valor (quantum debeatur) devido a título de danos extrapatrimoniais. Assim, ao julgar pedido de indenização por danos extrapatrimoniais, o juiz considerará: a) a natureza do bem jurídico tutelado; b) a intensidade do sofrimento ou da humilhação; c) a possibilidade de superação física ou psicológica; d) os reflexos pessoais e sociais da ação ou da omissão; e) a extensão e a duração dos efeitos da ofensa; f) as condições em que ocorreu a ofensa ou o prejuízo moral; g) o grau de dolo ou culpa; h) a ocorrência de retratação espontânea; i) o esforço efetivo para minimizar a ofensa; j) o perdão, tácito ou expresso; k) a situação social e econômica das partes envolvidas; l) grau de publicidade da ofensa.

No $\S 1^{\circ}$ do artigo 223-G da CLT, como visto, se encontram os parâmetros de valores para a indenização: a) natureza leve: até três vezes o último salário contratual; b) natureza média: até cinco vezes o último salário contratual; c) natureza grave: até vinte vezes o último salário contratual; d) natureza gravíssima: até cinquenta vezes o último salário contratual

Ademais, com a redação dada pela Reforma Trabalhista, o artigo 223-G, §1으, da CLT preceitua que o juiz do trabalho, ao julgar procedente o pedido indenizatório, deverá fixar as indenizações conforme a natureza da ofensa, sendo, esta, leve, média ou grave. No entanto esse posicionamento do legislador gera controvérsias, em razão da dificuldade em se definir, de forma objetiva, o que seria uma ofensa de natureza leve, média, grave ou gravíssima.

o legislador, ao redigir o dispositivo supramencionado, pretendeu que o juiz do trabalho enquadrasse a conduta de acordo com a natureza da ofensa moral, para, posteriormente, fixar os valores indenizatórios conforme a conduta enquadrada. Entretanto, na prática, essa tarefa pode ser bastante complexa.

Para fixação dos valores indenizatórios, a Reforma Trabalhista adotou como base o salário contratual do ofendido, desrespeitando, aparentemente, a ordem constitucional pátria, haja vista que os valores indenizatórios variam de acordo com a situação socioeconômica do ofendido, como se a dor do mais rico fosse mais importante do que a do mais pobre, fato esse, que, em uma primeira análise, fere os princípios e direitos fundamentais, como, por exemplo, o da isonomia, previsto no artigo 5을 $\mathrm{CF} / 1988$.

Nas relações de trabalho, as pessoas devem ser tratadas de forma isonômica pela lei, sem distinção de qualquer natureza. Além disso, é assegurado o direito a indenizações amplas dos danos extrapatrimoniais, decorrentes de relações de trabalho, a fim de que os danos sofridos pelos 
trabalhadores sejam reparados integralmente, nos termos do artigo 7º, XXVIII, XXX, XXXI e XXXII da CF/1988: <Art. 70 São direitos dos trabalhadores urbanos e rurais, além de outros que visem à melhoria de sua condição social: [...] XXVIII - seguro contra acidentes de trabalho, a cargo do empregador, sem excluir a indenização a que este está obrigado, quando incorrer em dolo ou culpa; [...] XXX - proibição de diferença de salários, de exercício de funções e de critério de admissão por motivo de sexo, idade, cor ou estado civil; [...] XXXI - proibição de qualquer discriminação no tocante a salário e critérios de admissão do trabalhador portador de deficiência; XXXII - proibição de distinção entre trabalho manual, técnico e intelectual ou entre os profissionais respectivos>.

A fixação da indenização conforme o salário do ofendido, aparentemente, além de ferir o direito constitucional de igualdade, colide com o princípio da dignidade da pessoa humana. Essa é imensurável, não tendo como ser precificada, tampouco ser objeto de discriminação conforme a situação socioeconômica da vítima.

Caso o lesado seja pessoa jurídica, os critérios para fixação das indenizações por danos extrapatrimoniais são os elencados no $\$ 1^{\circ}$ ㅇ do artigo 223 da CLT, entretanto, será com base no salário contratual do ofensor, conforme exposto no $\S 2$ o do dispositivo legal supracitado.

Consoante artigo 223-G, §3ํㅡㄹ da CLT, o juiz do trabalho poderá dobrar os valores indenizatórios, desde que haja reincidência entre partes idênticas. No entanto, na prática, possivelmente serão raras as situações nas quais as mesmas partes do processo sejam protagonistas em uma nova demanda. Assim, a limitação imposta pela Reforma Trabalhista fere o caráter preventivo e pedagógico da sanção, ao deixar de coibir a repetição dos mesmos atos no futuro.

Diante da ineficácia do dispositivo legal supramencionado, a incidência da reincidência nos pleitos indenizatórios decorrentes de condutas ofensivas à esfera moral do ofendido, devem ser aplicadas nos casos concretos, observando-se a reiteração da conduta, mesmo que as partes não sejam idênticas.

Por fim, ressalta-se que os critérios objetivos adotados pelo legislador reformista, previstos no $\S 1$ o do artigo 223 da CLT, não se aplicam aos danos extrapatrimoniais resultantes de morte.

\subsection{Ação direta de inconstitucionalidade 6.050}

A Associação Nacional dos Magistrados da Justiça do Trabalho (ANAMATRA) propôs ADI (número 6.050) perante o STF cujo pedido foi no sentido de que os incisos I, II, III e IV do $§ 1^{\text {o }}$ do artigo 223-G da CLT fossem declarados inconstitucionais, conforme os fundamentos expostos adiante.

A ADI 6.050 ainda não foi julgada, conforme certidão de 27.10.2021: <Decisão: Após o voto do Ministro Gilmar Mendes (Relator), que conhecia das ADI 6.050, 6.069 e 6.082 e julgava parcialmente procedentes os pedidos formulados, para conferir interpretação conforme a Constituição, de modo a estabelecer que: 1) As redações conferidas aos art. 223-A e 223-B, da CLT, não excluem o direito à reparação por dano moral indireto ou dano em ricochete no âmbito das relações de trabalho, a ser apreciado nos termos da legislação civil; 2) Os critérios de quantificação de reparação por dano extrapatrimonial previstos no art. 223-G, caput e $\S 1$ o, da CLT deverão ser observados pelo julgador como critérios orientativos de fundamentação da decisão judicial. É constitucional, porém, o arbitramento judicial do dano em valores superiores aos limites máximos dispostos nos incisos I a IV do $\S 1^{\circ}$ do art. 223-G, quando consideradas as circunstâncias do caso concreto e os princípios 
da razoabilidade, da proporcionalidade e da igualdade, pediu vista dos autos o Ministro Nunes Marques [...]>.

A autora da demanda alegou que a tarifação, imposta pela Reforma Trabalhista, gera limitação ao Poder Judiciário em estabelecer critérios mais amplos para fixação do montante indenizatório, com restrição à atuação dos juízes do trabalho.

Com o fim da vigência da Medida Provisória 808, ${ }^{21}$ os valores indenizatórios, que estavam sendo fixados sobre o limite máximo dos benefícios do Regime Geral de Previdência Social, voltaram a ser indexados conforme os salários contratuais dos ofendidos, resultando em valores indenizatórios discrepantes entre os trabalhadores. Assim, situações semelhantes terão valores diversos, somente pelo fato de as condições sociais serem diferentes entre as vítimas. Os ofendidos, que possuem salários superiores, terão indenizações maiores do que os que perceberem salários inferiores, fato esse que fere os princípios da isonomia, da razoabilidade, da proporcionalidade e da melhoria da condição social do trabalhador.

Além disso, argumentou a ANAMATRA que a Suprema Corte possui jurisprudência acerca da inconstitucionalidade da tarifação dos danos morais, na medida em que, no julgamento da ADPF 130, a Lei de Imprensa foi declarada inconstitucional, porquanto o artigo 5o, $V$ e $X$, da $\mathrm{CF} / 1988$ estabelece que as indenizações devem ser interpretadas de forma ampla, não podendo ser limitada por lei. Assim, a redação dos incisos I, II, III e IV do §1ํ do artigo 223-G da CLT, que fixam critérios objetivos para fixação dos valores indenizatórios decorrentes dos danos extrapatrimoniais, restringe as atividades jurisdicionais, devendo, portanto, serem os dispositivos declarados inconstitucionais, conforme entendimento consolidado pela Corte.

Por fim, a ANAMATRA alegou que os parâmetros de tarifação dos danos extrapatrimoniais estabelecidos pelo legislador, geram insegurança jurídica aos jurisdicionados.

A Procuradoria-Geral da República (PGR), por sua vez, manifestou-se pela inconstitucionalidade dos incisos I, II, III e IV do $\$ 1^{\text {o }}$ do artigo 223-G da CLT, além de ter requerido, por arrastamento, a inconstitucionalidade dos $\S \S 2^{\circ}$ e $3^{\circ}$ do artigo 223-G e dos artigos 223-A e 223-C da CLT.

Em contrapartida, a Advocacia-Geral da União (AGU) defendeu a constitucionalidade dos incisos I, II, III e IV do $\$ 1^{\circ}$ do artigo 223-G da CLT. Aduziu que os critérios adotados pelo legislador afastam o subjetivismo que permeia a matéria dos danos morais e encontram-se em sintonia com a CF/1988.

Segundo a AGU, a multiplicidade de fatores a serem analisados nos casos concretos, resultam em disparidades entre as decisões dos Tribunais, ao fixarem montantes indenizatórios distintos, em circunstâncias semelhantes, gerando, por consequência, uma situação de insegurança jurídica, ante a ausência de parâmetros objetivos. Portanto, esses critérios, estabelecidos pela Reforma Trabalhista, atendem aos princípios constitucionais da razoabilidade e da proporcionalidade, sem interferir nas atividades jurisdicionais.

0 critério legal de adoção do último salário contratual do ofendido como parâmetro de fixação do quantum indenizatório, para a AGU, obsta a concessão de indenização ínfimas ou exorbitantes. Evita que o padrão de vida dos lesados seja alterado em razão das indenizações oriundas dos danos sofridos na constância das relações de trabalho.

Para a AGU, a decisão proferida no julgamento da ADPF 130 não consolidou entendimento acerca da fixação de critérios objetivos para apuração dos danos extrapatrimoniais decorrentes das relações de trabalho. Tratava-se, no caso, de uma situação singular, de uma lei editada antes da $\mathrm{CF} / 1988$, cujo texto regulava as atividades da imprensa. 
Assim, a decisão proferida nos autos da sobredita ADPF, segundo a AGU, não analisou de forma determinante as hipóteses de tarifação legal dos danos extrapatrimoniais, mas somente em relação aos danos morais previstos especificamente na Lei de Imprensa, pugnando, portanto, pela constitucionalidade dos incisos I, II, III e IV do §1ํo do artigo 223-G da CLT.

Na próxima seção, serão sumarizados os argumentos desfavoráveis e favoráveis, ocasião na qual haverá resposta ao problema desta pesquisa.

\section{INCONSTITUCIONALIDADE DA TARIFAÇÃO DOS DANOS EXTRAPATRIMONIAIS}

Esta seção tratará de maneira específica do problema. A par de todo apanhado anterior, parece possível analisar se a tarifação do dano extrapatrimonial nas relações de trabalho, imposta pela Reforma Trabalhista, é, ou não, constitucional.

\subsection{Fundamentos favoráveis à tarifação dos danos extrapatrimoniais}

Nesta subseção, apresentar-se-ão os principais argumentos favoráveis à tarifação dos danos extrapatrimoniais, inseridos no $§ 1^{\circ}$ o do artigo $223-\mathrm{G}$ da CLT.

A adoção, pelo legislador, de critérios objetivos para fixar os valores indenizatórios, afasta a subjetividade existente nas decisões judiciais acerca dos danos extrapatrimoniais.

Os parâmetros elencados no $§ 1^{\circ}$ do art. 223 da CLT impedem os magistrados de exercerem livre-arbítrio para estabelecerem o quantum indenizatório, na medida em que os danos morais não possuem natureza infinita, devendo, portanto, serem estabelecido limites finitos para nortear as atividades jurisdicionais, com redução, assim, da incidência de montantes indenizatórios discrepantes, decorrentes de decisões judiciais distintas envolvendo casos concretos com circunstâncias semelhantes: <Ao nosso ver, a fixação de um teto mínimo e de um teto máximo na estimativa do quantum da reparação do dano moral, evidentemente, constitui medida válida para coibir abusos e excessos e deve ser adotada pelo legislador ordinário $>{ }^{22}$

A adoção desses critérios, minimamente, objetivos, não cerceia as atividades dos magistrados, porque a classificação quanto à natureza do dano (leve, médio, grave ou gravíssimo) é livre para ser definida pelo juiz do trabalho. Ademais, esse possui independência para fixar o quantum indenizatório, desde que devidamente fundamentado e respeitando os princípios da proporcionalidade, da isonomia, da legalidade e, obviamente, o limite máximo imposto pelo legislador.

A Reforma Trabalhista, ao redigir o dispositivo legal supramencionado, atentou-se em estabelecer limites para fixação dos valores indenizatórios, na medida em que inviabiliza a concessão de indenizações exageradas, que destoam da realidade, evitando, assim, que os padrões de vida do ofendido, bem como do ofensor sejam alterados em razão do quantum indenizatório, assegurando a segurança jurídica.

O dispositivo da Reforma Trabalhista não ataca diretamente os direitos e deveres fundamentais dos cidadãos, tendo sido expressa a vontade da maioria. Assim, os fundamentos para declarar a inconstitucionalidade do $\$ 1^{\circ}$ - do artigo 223 da CLT não podem ser pautados na valoração da norma, algo que ofenderia o Estado Democrático de Direito, e consequentemente a CF/1988: 
$<$ A Constituição, nesse tensionamento, exerce o papel fundador e estruturante necessário para harmonizar passado, presente e futuro e, portanto, constituir a sociedade. A Constituição, portanto, funciona com uma narrativa ficcional fundadora, um filtro de narratividade que, como ente imaginário, funda o Estado Democrático de Direito e é também fundada por ele, que é também um imaginário sócio-político-constitucional. ${ }^{23}$

Outrossim o legislador ao estabelecer o salário contratual do ofendido como parâmetro para fixar o quantum indenizatório, vislumbrou assegurar uma justa reparação à vítima e, com isso, evitou a ocorrência do enriquecimento sem causa, o que afastará, por consequência, a existência de um cenário de insegurança jurídica.

A decisão proferida nos autos da ADPF 130 trata de uma situação particular, na qual a tarifação dos danos morais, da Lei de Imprensa, foi declarada inconstitucional, na qual os artigos 51 e 52 do referido dispositivo legal estabeleciam hipótese concretas de tabelamento dos danos morais. No entanto a Reforma Trabalhista estabelece critérios objetivos abstratos e gerais para fixação dos danos extrapatrimoniais. Inexiste, portanto, o tabelamento dos danos morais, como evidenciado na Lei de Imprensa.

Nesse passo, a decisão judicial supracitada declarou inconstitucional as hipóteses de danos morais singulares aos profissionais de imprensa. Assim, a respectiva decisão versa sobre lei específica e não se estende, portanto, a todas as formas de tarifação legal dos danos extrapatrimoniais, conforme estabelece Enoque Ribeiro dos Santos: <Embora o Superior Tribunal de Justiça, pela Súmula no 281 tenha fixado o entendimento no sentido de que: 'A indenização por dano moral não está sujeita a tarifação prevista na Lei de Imprensa', cremos que o estabelecimento de critérios objetivos, como ora proposto pela Lei da Reforma Trabalhista (Lei n. 13.467/2017) promoverá uma parametrização do valor da reparação aos magistrados e aplicadores do direito, bem como uma maior previsibilidade e segurança jurídica aos atores sociais $>{ }^{24}$

Os critérios fixados pelo legislador da Reforma Trabalhista, assegura uma maior segurança jurídica, na medida em que estabelece limites proporcionais e razoáveis para fixação do quantum indenizatório, de forma coesa e coerente.

\subsection{Fundamentos contrários à tarifação dos danos extrapatrimoniais}

A fixação de dano moral sempre foi considerada uma tarefa demasiadamente difícil de ser realizada pelo magistrado, diante da falta de parâmetros pré-estabelecidos. Dessa feita, pelo mesmo fato danoso, haveria a estipulação de diversos valores.

No entendimento de Fonseca, o critério para a fixação dos danos materiais utilizado no direito brasileiro é o critério aberto: <0 critério utilizado para a definição dos valores a título de compensação por danos extrapatrimoniais tradicionalmente adotado pelo Judiciário brasileiro é o critério aberto, que se opõe ao critério fechado, legal ou tarifado de definição do quantum debeatur da indenização. Pelo critério aberto, o magistrado trabalhista, antes do advento da Lei no 13.467/17, analisava as circunstâncias do caso concreto para o arbitramento do valor indenizatório, analisando, no mais das vezes, a natureza da ofensa e do interesse extrapatrimonial lesado, o grau de culpa do ofensor, o comportamento da vítima e a condição econômica e social tanto do ofensor como do ofendido $>{ }^{25}$ 
Essa dificuldade, contudo, não autoriza a imposição de tarifação. Essa posição é a adotada neste estudo.

Os parâmetros de tarifação dos danos extrapatrimoniais, estipulados pelo legislador da Reforma Trabalhista, reduzem a margem de discricionariedade dos magistrados, na medida em que foram, previamente, estabelecidos critérios objetivos para fixar os valores indenizatórios decorrentes dos danos extrapatrimoniais oriundos das relações de trabalho, conforme se extrai do seguinte trecho: < No caso em exame, o §1ํ do art. 223-G elegeu o critério da natureza da ofensa, se leve, média, grave ou gravíssima, cabendo ao juiz definir na sentença qual é a natureza da ofensa extrapatrimonial para a observância dos tetos previstos nos incisos do dispositivo em comento. ${ }^{26}$

Reconhecido o direito à reparação do dano moral, os elementos que informam a liquidação diferem do caso do dano material. Na reparação do dano material, identifica-se facilmente o valor devido ao lesado. Todavia, na reparação do dano moral, certas particularidades devem ser evidenciadas. A indenização não visa ressarcir, porém sim compensar a vítima, sendo a reparação pecuniária uma medida para compensar os danos causados aos ofendidos.

Nesse sentido, Correia e Miessa aduzem que realmente havia posicionamento que abordava a necessidade da tarifação do dano extrapatrimonial: <Tendo em vista a análise casuística, existe o posicionamento que defende a criação de critérios objetivos para a fixação do valor da indenização como forma de assegurar maior previsibilidade na indenização devida. É o denominado sistema de tarifação do dano moral>. ${ }^{27}$

Segundo Delgado, os dispositivos legais contidos no novo Título II-A da CLT descaracterizam preceitos fundamentais, positivados pela CF/1988, pois, equalizam situações jurídicas distintas, divergindo do princípio da centralidade da pessoa humana no ordenamento jurídico brasileiro, atrelado ao princípio da dignidade da pessoa humana: <0 novo Título II-A da CLT, ao reverso, tenta descaracterizar esse avanço cultural e jurídico, por meio de nítida equalização de situações e conceitos jurídicos diversos. Segundo a literalidade da nova Lei, não cabe mais falar em dano moral, dano estético e correlatos: simplesmente despontam os danos extrapatrimoniais, quer de trabalhadores, quer de empresas, que se tornam bastante similares e equivalentes, aparentemente desvestidos da força constitucional inspiradora deflagrada em 1998 em benefício da pessoa humana. ${ }^{28}$

As normas em questão mostram-se ineficazes ao regulamentar a aplicação do instituto dos danos extrapatrimoniais, e, no que tange à proteção da pessoa humana, resulta em um cenário de insegurança jurídica, o que fere, portanto, os preceitos fundamentais da CF/1988.

A CF/1988, em seu artigo 5ํ, V e X, assegura o direito e garantia a uma indenização por danos morais, ampla e proporcional ao agravo, quando violada a personalidade dos indivíduos, relacionando-se, também, com o princípio da dignidade da pessoa humana. Por efeito, em conformidade com os preceitos constitucionais, qualquer forma de limitação imposta aos danos extrapatrimoniais se reportará como inconstitucional: <A honra é um direito de personalidade (ligado à pessoa humana) referente à integridade moral do indivíduo; ademais, pode ser relacionada aos direitos fundamentais e à dignidade da pessoa humana. Sob essa óptica, e tomandose por base o contexto de um Estado Democrático de Direito, pode-se perceber que o direito em questão é de extrema importância para o desenvolvimento da sociedade. $>^{29}$

No entanto, o legislador da Reforma Trabalhista, contrariando a ordem constitucional, estabeleceu, previamente, critérios objetivos que o juiz do trabalho deverá observar ao fixar 
o quantum indenizatório dos danos extrapatrimoniais, em evidente restrição à atuação dos magistrados na Justiça do Trabalho.

Ademais, em um ordenamento jurídico, observa-se a existência de um conjunto de normas que, harmonicamente, seguem uma hierarquia entre si, isto é, as normas inferiores retiram sua eficácia e validade das normas hierarquicamente superiores.

O escalonamento jurídico pátrio, como é de sabença, possui a CF/1988 em seu vértice, cuja previsão é o fundamento de validade das demais normas jurídicas. Consequentemente, as normas infraconstitucionais devem estar em conformidade com a ordem constitucional, sob pena de serem consideradas inconstitucionais.

A tarifação dos danos extrapatrimoniais, instituída pela Reforma Trabalhista, nesse cenário, contraria a CF/1988. Esta inadmite a fixação de limites à reparação integral dos danos, o que evidencia, portanto, a existência de uma antinomia entre as normas, na medida em que a norma infraconstitucional se opõe às disposições da norma hierarquicamente superior, devendo ser declarada a inconstitucionalidade da taxatividade prevista no $§ 1^{\circ} \mathrm{o}$ do art. 223 da CLT.

Além disso, a ordem jurídica-constitucional consagra o princípio da separação dos poderes, ao assegurar a relação de independência e harmonia entre os órgãos do poder político brasileiro, conforme expõe o artigo $2^{\circ}$ da CF/1988. Nesse passo, o Judiciário possui a prerrogativa de julgar as demandas conforme os ditames dos direitos e garantias fundamentais, sem qualquer liame de subordinação ou dependência relativamente aos demais órgãos do poder político do Estado. Assim, o Legislativo não poderá interferir na atuação do Judiciário, sob pena de transgredir a relação harmônica e de independência entre os três poderes.

Diante disso, percebe-se que o legislador reformista interferiu diretamente na atuação do Poder Judiciário, no que tange ao condicionamento das decisões judiciais aos critérios objetivos previamente estabelecidos pelo $\$ 1^{\circ}$ do art. 223 da CLT, restringindo, portanto, a capacidade de discricionariedade e do juízo de proporcionalidade dos magistrados, na medida em que estes foram vedados de proferirem indenizações, por danos extrapatrimoniais, que ultrapassem os limites fixados pelo legislador, violando, portanto, as diretrizes do principio constitucional da separação dos poderes.

Outro argumento diz respeito ao princípio da isonomia cujo conteúdo garante o direito de igualdade entre os cidadãos brasileiros, sem que haja distinção de qualquer natureza, expresso no artigo 5ㅜ, caput, da CF/1988, considerado um dos pilares da democracia: <A partir do Estado Democrático de Direito sugerido pelo texto constitucional, a cidadania no Brasil deve ser reestruturada, principalmente à luz dos ideais transformadores desse modelo de Estado, que sugerem, principalmente, a melhoria das condições sociais no Brasil. $>^{30}$

No plano das relações de trabalho, essa isonomia se evidencia no artigo 7ํ, XXVIII, XXX, XXXI e XXXII da CF/1988. Dessa forma, o legislador é impedido de criar ou editar leis que violem esse princípio constitucional.

Martinez aduz que, o tabelamento inserido pelo legislador da Reforma Trabalhista, colide com o princípio constitucional da proporcionalidade e que a utilização do último salário contratual do ofendido como parâmetro para fixação do quantum indenizatório, fere a dignidade da pessoa humana, na medida em que correlaciona a dignidade do lesado com seus salários percebidos, conforme se extrai do seguinte trecho: < [...] grande problema da Lei n. 13.467/2017 reside, porém, na tentativa de tarifar a dimensão da violação ao patrimônio imaterial, que, como qualquer outro dano, se deveria, em verdade, medir por sua extensão (vide o art. 944 do Código Civil). Esse atuar 
legislativo afronta claramente o texto constitucional que, nos termos do inciso V do seu art. 5.․ㅡ, assegura o direito de resposta, proporcional ao agravo. Não fosse apenas isso, a tarifação imposta pela lei tem por baliza o 'último salário contratual do ofendido', o que pode fazer com que um mesmo bem jurídico ofendido venha a merecer indenizações em dimensões extremamente diferentes,

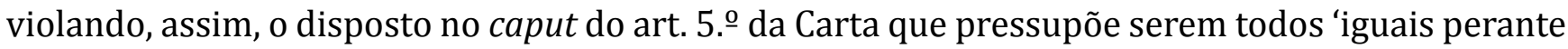
a lei, sem distinção de qualquer natureza'. A distinção aqui seria de natureza financeira $>^{31}$

A utilização dos salário contratual do ofendido como critério para indexar o quantum indenizatório dos danos extrapatrimoniais, viola os princípios da igualdade e da proporcionalidade, porquanto situações decorrentes da violação de um mesmo dano resultam em valores indenizatórios distintos, variando de acordo com os salários do ofendido, o que evidencia atos discriminatórios na medida em que as vítimas são discriminadas conforme suas condições sociais, isto é, a dignidade do ofendido está condicionada aos salários percebidos, em desrespeito aos princípios da dignidade da pessoa humana, da isonomia, e da proporcionalidade.

A adoção do último salário contratual do ofendido como parâmetro para fixação da indenização, reflete um tratamento desigual entre as vítimas, porque em situações semelhantes de danos à esfera da personalidade dos indivíduos, os valores indenizatórios serão distintos, não em razão da amplitude, da natureza ou da gravidade das ofensas, mas, exclusivamente, em razão dos salários percebidos. Assim, o $§ 1^{\circ}$ do art. 223 da CLT discrimina o sofrimento dos trabalhadores conforme sua condição social, sendo, portanto, inadmissível à luz do postulado isonômico: <0 que a lei faz é exatamente isto: embora os trabalhadores sejam merecedores de igual tratamento digno, eles devem ser separados de acordo com seus salários, para fins de mensuração de seu patrimônio moral. Quanto menor o salário, menor será a reparação da dignidade do trabalhador. Ou, em outras palavras, a dignidade e o patrimônio moral do trabalhador são proporcionais ao seu valor no mercado de trabalho $>{ }^{32}$

O princípio da dignidade da pessoa humana e os valores sociais do trabalho e da livre-iniciativa são fundamentos para constituição do Estado Democrático de Direito, nos moldes dos incisos III e IV do art. 1ํo da CF/1988. A utilização dos salários contratuais dos ofendidos, como critério para fixar as indenizações, caracteriza-se como uma medida antidemocrática, configurando-se como uma forma de precificação dos direitos inerentes à personalidade dos indivíduos, condicionando a dignidade dos ofendidos aos seus valores no mercado de trabalho: <0s direitos fundamentais constituem fundamentos do Estado democrático de direito e são inerentes ao princípio fundamental da dignidade da pessoa humana, eis que o arcabouço de direitos fundamentais gravita em torno da garantia de proteção da dignidade do indivíduo $>.^{33}$

Assim, demonstra-se a flagrante inconstitucionalidade da tarifação dos danos extrapatrimoniais, havendo o desrespeito ao princípio da isonomia. Se a intenção era fixar um parâmetro, este deveria ser universal, ou seja, não se pautar no último salário contratual. 0 estabelecimento desses valores faria com que danos idênticos pudessem ser indenizados com valores divergentes, devido ao salário contratual do lesado.

Cabe lembrar que, no ordenamento jurídico brasileiro, o Código Brasileiro de Telecomunicações e a Lei de Imprensa previam um valor fixado a título de danos morais, mas com a promulgação da CF/1988, rejeitou-se a tarifação desses danos. Nesse sentido, de acordo com o entendimento do STF, no RE n. 396386-4, e do STJ, na Súmula 281, a indenização por danos extrapatrimoniais não está sujeita a tarifação, porquanto deve ser ampla e na proporção da ofensa. 
0 STF, como visto, no julgamento da ADPF 130, fixou entendimento acerca da inconstitucionalidade da taxatividade das indenizações por danos morais, tendo em vista que a tarifação acerca dos valores indenizatórios viola os preceitos constitucionais de igualdade e proporcionalidade.

Nas palavras de Barba Filho, a Suprema Corte tende a declarar a inconstitucionalidade dos dispositivos legais contidos no novo Titulo II-A da Lei 13.467/17, referentes à tarifação dos danos extrapatrimoniais, conforme se extrai do seguinte trecho: $<\mathrm{A}$ iniciativa da Reforma, quanto a este tema, não ataca rigorosamente nenhum dos elementos que levaram o STF a declarar que a Lei de Imprensa não fora recepcionada pela Constituição Federal, e nenhum dos fundamentos específicos que já haviam sido aventados naquela oportunidade a respeito da inviabilidade da legislação ordinária estabelecer qualquer tarifação relativamente à indenização por danos morais. Nesse cenário, a não ser que o STF de forma surpreendente venha a afrontar a ratio decidende de diversos de seus precedentes a respeito dessa temática, a tendência natural é que se declare a inconstitucionalidade dos $\S \S 1^{1}$, $2^{\circ}$ o e 3o do art. 223-G introduzidos à CLT pela lei 13467/17>. ${ }^{34}$

Dessa forma, conforme entendimento consolidado pelo STF, faz-se necessário a declaração de inconstitucionalidade da taxatividade dos danos extrapatrimoniais no direito do trabalho: <De acordo com nosso entendimento, reforçado pelo posicionamento adotado pelo Ministério Público do Trabalho, o sistema de tarifação do dano moral nas relações de trabalho é inconstitucional, pois impõe limite injustificado ao valor a ser indenizado àquele que sofreu o dano, o que pode impedir sua reparação integral. Nesse sentido, o juiz deve balizar sua decisão em critérios razoáveis para fixar a quantia devida a título de danos morais, sempre pautado pelo 'princípio de que o dano não pode ser fonte de lucro'.> 35

Portanto, as indenizações por danos morais devem ser interpretadas de forma ampla, sem qualquer tentativa de restrição, conforme incisos V e X do art. 5o da CF/1988. Descaberia, portanto, ao legislador da Reforma Trabalhista impor critérios objetivos de tarifação acerca do valor dos danos extrapatrimoniais decorrentes das relações de trabalho.

Diante de todo o exposto, a Reforma Trabalhista afastou a proteção e tornou o empregado vulnerável, e, consequentemente, a dignidade da pessoa humana, ao passo que comparou o trabalhador a uma coisa, estimando o dano extrapatrimonial pelo seu patrimônio, devendo, portanto, ser declarada a inconstitucionalidade dos incisos I, II, III e IV do §1ำ do artigo 223-G da CLT.

\section{CONSIDERAÇÕES FINAIS}

Este trabalho analisou os fundamentos acerca constitucionalidade da tarifação dos danos extrapatrimoniais, prevista na CLT e inserida pela Reforma Trabalhista, a fim de obter a solução para o problema de pesquisa.

Evidenciou-se que os atos ilícitos praticados por terceiros, que violem os direitos de personalidade dos indivíduos, caracterizam-se como danos morais, o que assegura aos ofendidos indenizações em sentido amplo, diante do princípio da reparação integral dos danos sofridos.

A pesquisa também patenteou que os Tribunais Superiores consolidaram entendimento no sentido da inaplicabilidade da tarifação dos danos morais. 
No que tange aos critérios de tarifação do valor do dano moral, inseridos pelo legislador reformista, houve interferência na atuação do Poder Judiciário, ao condicionar as decisões judiciais aos parâmetros fixados no artigo 223-G da CLT.

As limitações impostas aos magistrados, na fixação dos valores indenizatórios, impedem a concretização do princípio da reparação integral dos danos, na medida em que os juízes do trabalho não poderão estabelecer montantes superiores aos fixados no §1ำ do artigo 223-G da CLT. Desse modo, as indenizações não serão concedidas em sentido amplo, o que contraria a ordem constitucional.

A adoção do último salário contratual do ofendido, como parâmetro na fixação do quantum indenizatório, discrimina os trabalhadores em razão dos salários percebidos, bem como acentua as desigualdades sociais existentes nas relações de trabalho, além de configurar uma precificação da dignidade dos trabalhadores. A medida, portanto, viola os princípios da dignidade da pessoa humana, da isonomia e da proporcionalidade.

As alterações inseridas na CLT pela Reforma Trabalhista, principalmente no que concerne ao tabelamento dos danos extrapatrimoniais previsto nos incisos I, II, III e IV do $\$ 1^{\text {o }}$ do artigo 223-G da CLT, portanto, possui vícios insanáveis de inconstitucionalidade.

\section{BIBLIOGRAFIA}

Barba Filho, Roberto Dala. (2017). A inconstitucionalidade da tarifação da indenização por dano extrapatrimonial no direito do Trabalho. Revista Eletrônica do Tribunal Regional do Trabalho da 9a Região. V. 7, n. 63. Disponível em: https://juslaboris.tst.jus.br/bitstream/handle/20.500.12178/1225 54/2017_barba_filho_inconstitucionalidade_tarifacao.pdf?sequence=1\&isAllowed=y.

Casagrande, Cássio. (2017). A reforma trabalhista e a inconstitucionalidade da tarifação do dano moral com base no salário do empregado. Revista Jurídica da Escola Superior de Advocacia da OAB-PR. Ano 2, n. 3. Disponível em: http://revistajuridica.esa.oabpr.org.br/wp-content/uploads/2017/12/19122017_rev ista_esa_5_dezembro_5.pdf.

Cassar, Vólia Bomfim. (2017). Direito do trabalho de acordo com a reforma trabalhista. 14. ed. Rio de Janeiro: Forense.

Copi, Irving M. (1978). Introdução à lógica. 2. ed. São Paulo: Mestre Jou.

Correia, Henrique. Miessa, Élisson. (2018). Manual da reforma trabalhista. Salvador: JusPodivm.

Delgado, Mauricio Godinho. (2019). Curso de direito do trabalho. 18. ed. São Paulo: LTr.

Fonseca, Bruno Gomes Borges da (2019). Direito humano e fundamental ao Trabalho. Curitiba: Editora CRV.

Fonseca, Rodrigo Dias da. (2018). Reforma trabalhista comentada., Florianópolis: Empório do Direito.

Gonçalves, Carlos Roberto. (2017). Direito civil brasileiro: direito de familia. 14. ed. São Paulo: Saraiva.

Gonçalves, Carlos Roberto. (2008). Direito civil brasileiro: responsabilidade civil. 3. ed. São Paulo: Saraiva.

Karam, Henriete. Espindola, Angela Araujo da Silveira. (2019). Constitucionalismo contemporâneo e constituição ficcional fundadora: o caráter construtivo e fictício das interpretações à luz da matriz direito-literatura. Revista de Direitos e Garantias Fundamentais. V. 20, n. 3. Disponível em: http://sisbi b.emnuvens.com.br/direitosegarantias/article/view/1797.

Leite, Carlos Henrique Bezerra. (2019). Curso de direito do Trabalho. 11. ed. São Paulo: Saraiva.

Martinez, Luciano. (2018). Reforma trabalhista - entenda o que mudou: CLT comparada e comentada. 2 ed. São Paulo: Saraiva Educação.

Moraes, Alexandre de. (2002). Constituição do Brasil interpretada e legislação constitucional. São Paulo: Atlas. 
Morais, Jose Luis Bolzan de. Moreira, Nelson Camatta. (2019). Constitucionalismo, Estado de Direito e a invisibilidade social que teima em continuar. Revista de Direitos e Garantias Fundamentais. V. 20, n. 3. Disponível em: http://sisbib.emnuvens.com.br/direitosegarantias/article/view/1798.

Nader, Paulo. (2016). Curso de direito civil. 6. ed. rev. atual. e ampl. Rio de Janeiro: Forense.

Pontin, Ana Paula Dutra. (2016). 0 meio ambiente do trabalho equilibrado como pressuposto da dignidade humana do trabalhador. Livros do Conibdh: direitos humanos fundamentais II. Vitória: FDV Publicações. Disponível em: http://site.fdv.br/livros-do-conibdh-direitos-fundamentais-ii/.

Rezende, Vítor Pizol de. (2016). Assédio moral no trabalho: relação entre dignidade da pessoa humana e indenização por danos morais sob a perspectiva do TRT-ES. Livros do Conibdh: direitos humanos fundamentais II. Vitória: FDV Publicações. Disponível em: http://site.fdv.br/livros-do-conibdh-direito s-fundamentais-ii/.

Sanseverino, Paulo de Tarso Vieira. (2010). Princípio da reparação integral: indenização no Código Civil. São Paulo: Atlas.

Santos, Enoque Ribeiro dos. (2017). 0 dano extrapatrimonial na lei n. 13.467/2017, da Reforma Trabalhista. Revista Eletrônica do Tribunal Regional do Trabalho da 9a Região. V. 7, n. 62, p. 68. Disponível em: https://juslaboris.tst.jus.br/bitstream/handle/20.500.12178/158110/2019_santos_enoque_dan o_extrapatrimonial.pdf?sequence $=1$ \&isAllowed $=\mathrm{y}$.

Silva, Homero Mateus da. (2017). Comentários à reforma trabalhista. 2. ed. rev. e atual. São Paulo: Editora Revista dos Tribunais.

Tartuce, Flávio. (2017). Direito civil: direito de familia. 12. ed. Rio de Janeiro: Forense.

\section{REPERTÓRIOS LEGISLATIVO E JURISPRUDENCIAL}

Constituição [da] República Federativa do Brasil, promulgada em 5 de outubro de 1988. Disponível em: htt p://www.planalto.gov.br/ccivil_03/Constituicao/Constituicao.htm.

Decreto-Lei 5.452/1943, de 1o de maio, Consolidação das Leis do Trabalho. Disponível em: http://www.pl analto.gov.br/ccivil_03/decreto-lei/del5452.htm.

Lei 4.117/1962, de 27 de agosto. Institui o Código Brasileiro de Telecomunicações. Disponível em: http://w ww.planalto.gov.br/ccivil_03/leis/14117compilada.htm.

Lei 5.250/1967, de 9 de fevereiro. Regula a liberdade de manifestação do pensamento e de informação. Disponível em: http://www.planalto.gov.br/ccivil_03/leis/l5250.htm\#: :text=LEI\%20No\%205.250 \%2C\%20DE\%209\%20DE\%20FEVEREIRO\%20DE\%201967.\&text=Regula\%20a\%20liberdade\%20de \%20manifesta\%C3\%A7\%C3\%A3o\%20do\%20pensamento\%20e\%20de\%20informa $\%$ C3\%A7\%C3\% A3o.\&text=Art $\% 20 . \&$ text $=\% \mathrm{C} 2 \% \mathrm{~A} 7 \% 201 \% \mathrm{C} 2 \% \mathrm{BA} \% 20 \mathrm{~A} \% 20 \mathrm{explora} \% \mathrm{C} 3 \% \mathrm{~A} 7 \% \mathrm{C} 3 \% \mathrm{~A} 3 \mathrm{o} \% 20 \mathrm{dos}, \mathrm{fe}$ deral\%2C\%20na\%20forma\%20da\%20lei.

Lei 10.406/2002, de 11 janeiro, Código Civil. Disponível em: http://www.planalto.gov.br/ccivil_03/leis/20 02/l10406.htm.

Lei 13.467/2017, de 13 de julho, Reforma Trabalhista. Disponível em: http://www.planalto.gov.br/ccivil_0 3/_ato2015-2018/2017/lei/L13467.htm.

Medida Provisória 808/2017, de 14 de novembro. Altera a Consolidação das Leis do Trabalho - CLT, aprovada pelo Decreto-Lei n o 5.452, de 1 o de maio de 1943. Disponível em: http://www.planalto.gov.br/ccivil _03/_ato2015-2018/2017/mpv/mpv808.htm.

Superior Tribunal de Justiça. Recurso especial 3474491. Disponível em: https://processo.stj.jus.br/processo /pesquisa/?tipoPesquisa=tipoPesquisaNumeroRegistro\&termo=200101088382\&totalRegistrosPorP agina $=40 \&$ aplicacao $=$ processos.ea. 
Superior Tribunal de Justiça. Súmula 281. Disponível em: https://bit.ly/2N0G2Va.

Supremo Tribunal Federal. Ação direta de inconstitucionalidade 6050. Disponível em: http://portal.stf.jus. $\mathrm{br} /$ processos $/$ detalhe.asp?incidente $=5612680$.

Supremo Tribunal Federal. Arguição de descumprimento de preceito fundamental 130. Disponível em: $\underline{\text { http }}$ ://portal.stf.jus.br/processos/detalhe.asp?incidente=12837.

Supremo Tribunal Federal. Recurso extraordinário 396386. Disponível em: http://portal.stf.jus.br/process os/detalhe.asp?incidente $=2147269$.

\section{NOTAS}

1 Lei 13.467/2017, de 13 de julho, Reforma Trabalhista. Disponível em: http://www.planalto.gov.br/ccivil_03/_ato2 015-2018/2017/lei/L13467.htm. Os atos normativos e as decisões judiciais, com o escopo de conferir maior fluidez ao texto, apenas serão referenciados por nota de rodapé na primeira citação, sem prejuízo de seu registro na bibliografía e nos repertórios legislativo e jurisprudencial.

2 Constituição [da] República Federativa do Brasil, promulgada em 5 de outubro de 1988. Disponível em: $\underline{\text { http:/l }}$ www.planalto.gov.br/ccivil_03/Constituicao/Constituicao.htm.

3 Decreto-Lei 5.452/1943, de $1^{\circ}$ de maio, Consolidação das Leis do Trabalho. Disponível em: http://www.planalto .gov.br/ccivil_03/decreto-lei/del5452.htm.

4 Supremo Tribunal Federal. Ação direta de inconstitucionalidade 6050. Disponível em: http://portal.stf.jus.br/p rocessos/detalhe.asp?incidente $=5612680$.

5 Gonçalves, Carlos Roberto. (2017). Direito civil brasileiro: direito de familia. 14. ed. São Paulo: Saraiva, p. 424.

6 Correia, Henrique. Miessa, Élisson. (2018). Manual da reforma trabalhista. Salvador: JusPodivm, p. 270.

7 Moraes, Alexandre de. (2002). Constituição do Brasil interpretada e legislação constitucional. São Paulo: Atlas, p. 128.

8 Lei 10.406/2002, de 11 janeiro, Código Civil. Disponível em: http://www.planalto.gov.br/ccivil_03/leis/2002/l104 06.htm.

9 Gonçalves, Carlos Roberto. (2008). Direito civil brasileiro: responsabilidade civil. 3. ed. São Paulo: Saraiva, p. 359.

10 Nader, Paulo. (2016). Curso de direito civil. 6. ed. rev. atual. e ampl. Rio de Janeiro: Forense, p. 54.

11 Sanseverino, Paulo de Tarso Vieira. (2010). Princípio da reparação integral: indenização no Código Civil. São Paulo: Atlas, p. 48.

12 Lei 4.117/1962, de 27 de agosto. Institui o Código Brasileiro de Telecomunicações. Disponível em: http://www.p lanalto.gov.br/ccivil_03/leis/l4117compilada.htm.

13 Lei 5.250/1967, de 9 de fevereiro. Regula a liberdade de manifestação do pensamento e de informação. Disponível em: http://www.planalto.gov.br/ccivil_03/leis/l5250.htm\#: :text=LEl\%20No\%205.250\%2C\%20DE\%209 \%20DE\%20FEVEREIRO\%20DE\%201967.\&text=Regula\%20a\%2oliberdade\%20de\%20manifesta\%C3\%A7\%C3\%A30\%20d o\%20pensamento\%20e\%20de\%20informa\%C3\%A7\%C3\%A30.\&text=Art\%20.\&text=\%C2\%A7\%201\%C2\%BA\%20A\%20ex plora\%C3\%A7\%C3\%A30\%20dos,federal\%2C\%20na\%20forma\%20da\%20lei.

14 Supremo Tribunal Federal. Arguição de descumprimento de preceito fundamental 130. Disponível em: http://p ortal.stf.jus.br/processos/detalhe.asp?incidente=12837.

15 Superior Tribunal de Justiça. Súmula 281. Disponível em: https://bit.ly/2NoG2Va.

16 Supremo Tribunal Federal. Recurso extraordinário 396386. Disponível em: http://portal.stf.jus.br/processos/de talhe.asp?incidente $=2147269$.

17 Superior Tribunal de Justiça. Recurso especial 3474491. Disponível em: https://processo.stj.jus.br/processo/pesq uisa/?tipoPesquisa=tipoPesquisaNumeroRegistro\&termo=200101088382\&totalRegistrosPorPagina $=40 \& a p l i c a$ cao=processos.ea.

18 Fonseca, Bruno Gomes Borges da. (2019). Direito humano e fundamental ao Trabalho. Curitiba: Editora CRV.

19 Leite, Carlos Henrique Bezerra. (2019). Curso de direito do Trabalho. 11. ed. São Paulo: Saraiva, p. 69.

20 Tartuce, Flávio. (2017). Direito civil: direito de familia. 12. ed. Rio de Janeiro: Forense, p. 489. 
Medida Provisória 808/2017, de 14 de novembro. Altera a Consolidação das Leis do Trabalho - CLT, aprovada pelo Decreto-Lei ${ }^{\circ}{ }^{5}$.452, de $1^{\circ}$ de maio de 1943 . Disponível em: http://www.planalto.gov.br/ccivil_03/_ato20 $15-2018 / 2017 / \mathrm{mpv} / \mathrm{mpv} 808$.htm

22 Silva, Homero Mateus da. (2017). Comentários à reforma trabalhista. 2. ed. rev. e atual. São Paulo: Editora Revista dos Tribunais, p. 389.

23 Karam, Henriete. Espindola, Angela Araujo da Silveira. (2019). Constitucionalismo contemporâneo e constituição ficcional fundadora: o caráter construtivo e fictício das interpretações à luz da matriz direitoliteratura. Revista de Direitos e Garantias Fundamentais. V. 20, n. 3, p. 6. Disponível em: http://sisbib.emnuven s.com.br/direitosegarantias/article/view/1797.

24 Santos, Enoque Ribeiro dos. (2017). O dano extrapatrimonial na lei n. 13.467/2017, da Reforma Trabalhista. Revista Eletrônica do Tribunal Regional do Trabalho da 9a Região. V. 7, n. 62, p. 68. Disponível em: https://juslaboris.tst.jus.br/bitstream/handle/20.500.12178/158110/2019_santos_enoque_dano_extrapatrim onial.pdf? sequence=1\&isAllowed $=y$.

25 Fonseca, Rodrigo Dias da. (2018). Reforma trabalhista comentada. Florianópolis: Empório do Direito, p. 17.

26 Fonseca, Rodrigo Dias da, op. cit., p. 24.

27 Correia, Henrique. Miessa, Élisson, op. cit., p. 294.

28 Delgado, Mauricio Godinho. (2019). Curso de direito do Trabalho. 18. ed. São Paulo: LTr, p. 785.

29 Rezende, Vítor Pizol de. (2016). Assédio moral no trabalho: relação entre dignidade da pessoa humana e indenização por danos morais sob a perspectiva do TRT-ES. Livros do Conibdh: direitos humanos fundamentais II. Vitória: FDV Publicações, p. 49. Disponível em: http://site.fdv.br/livros-do-conibdh-direitos-fundamentais-ii/.

30 Morais, Jose Luis Bolzan de. Moreira, Nelson Camatta. (2019). Constitucionalismo, Estado de Direito e a invisibilidade social que ‘teima' em continuar. Revista de Direitos e Garantias Fundamentais. V. 20, n. 3, p. 16. Disponível em: http://sisbib.emnuvens.com.br/direitosegarantias/article/view/1798.

31 Martinez, Luciano. (2018). Reforma trabalhista - entenda o que mudou: CLT comparada e comentada. 2 ed. São Paulo: Saraiva Educação.

32 Casagrande, Cássio. (2017). A reforma trabalhista e a inconstitucionalidade da tarifação do dano moral com base no salário do empregado. Revista Jurídica da Escola Superior de Advocacia da OAB-PR. Ano 2, n. 3, p. 68. Disponível em: http://revistajuridica.esa.oabpr.org.br/wp-content/uploads/2017/12/19122017_revista_esa_5_dez embro_5.pdf.

33 Pontin, Ana Paula Dutra. (2016). O meio ambiente do trabalho equilibrado como pressuposto da dignidade humana do trabalhador. Livros do Conibdh: direitos humanos fundamentais II. Vitória: FDV Publicações, p. 25. Disponível em: http://site.fdv.br/livros-do-conibdh-direitos-fundamentais-ii/.

34 Barba Filho, Roberto Dala. (2017). A inconstitucionalidade da tarifação da indenização por dano extrapatrimonial no direito do Trabalho. Revista Eletrônica do Tribunal Regional do Trabalho da 9a Região. V. 7, n. 63, p. 192. Disponível em: https://juslaboris.tst.jus.br/bitstream/handle/20.500.12178/122554/2017_barba_fil ho inconstitucionalidade tarifacao.pdf? sequence=1\&isAllowed $=y$.

35 Correia, Henrique. Miessa, Élisson, op. cit., p. 295. 